\title{
Evidence, limes, and cement
}

In the 1990s, Sackett et $\mathrm{al}^{1}$ popularized the term evidence-based medicine, ie, the evaluation and use of clinical research in decision-making for individual patients. Some have not embraced evidence-based medicine as the be-all and end-all of clinical decision-making, and we should not expect clinical studies to tell us what to do in every decision that we make at the bedside. Nonetheless, almost everyone accepts the well-done randomized, placebo-controlled study as the most powerful tool in the evidence-based medicine toolbox.

In 1753, Lind ${ }^{2}$ described how he gave fresh fruit vs cider, vinegar, sulfuric acid, seawater, or barley water to 12 sailors aboard the HMS Salisbury in an effort to find a cure for scurvy. This landmark clinical trial has been hailed as an example of how clinical research can dramatically alter clinical practice. Yet practice did not change aboard British naval ships until almost 50 years after Lind's treatise was published. ${ }^{3}$

For many reasons, randomized clinical trials may not immediately affect what physicians do. Sometimes, physicians believe that the trials were not well designed or well conducted, or that the results do not apply to their patients. I briefly discussed some limitations of evidence-based clinical decision-making in our September 2009 issue. $^{4}$

Another reason is that the conclusions from some trials do not jibe with the experience of seasoned clinicians. That is why, this month, I have asked two physicians, a rheumatologist (page 12) ${ }^{5}$ and a spine surgeon (page 8), ${ }^{6}$ to comment on how two studies $^{7,8}$ have influenced their clinical practice. Both studies concluded that vertebroplasty (injecting cement to shore up osteoporotic vertebrae) was no more beneficial than a sham procedure in patients with vertebral compression fractures. Neither physician is ready to completely abandon vertebroplasty on the basis of these two studies. Thus, it seems that published evidence may provide us guidance and fruit for discussion, but does not give us certainty.

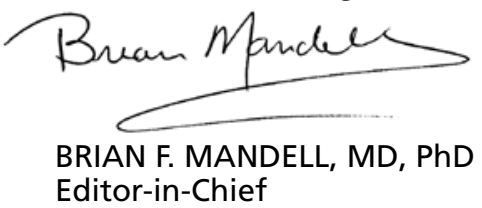

\section{REFERENCES}

1. Sackett DL, Rosenberg WM, Gray JA, Haynes RB, Richardson WS. Evidence based medicine: what it is and what it isn't [editorial]. BMJ 1996; 312:71-72.

2. Lind J. Treatise of the Scurvy in Three Parts. Containing an inquiry into the Nature, Causes and Cure of that Disease. Together with a Critical and Chronological View of what has been published on the subject. Edinburgh: Sands, Murray, and Cochran, 1753.

3. Carpenter K. The History of Scurvy and Vitamin C. Cambridge, UK: Cambridge University Press, 1988.

4. Mandell BF. Vertebroplasty, evidence, and health care reform: What is quality care? Cleve Clin J Med 2009; 76:497-502.

5. Bolster MA. Consternation and questions about two vertebroplasty trials. Cleve Clin J Med 2010; 77:12-16.

6. Orr RD. Vertebroplasty, cognitive dissonance, and evidence-based medicine: what do we do when the 'evidence' says we are wrong? Cleve Clin J Med 2010; 77:8-11.

7. Kallmes DF, Comstock BA, Heagerty PJ, et al. A randomized trial of vertebroplasty for osteoporotic spinal fractures. N Engl J Med 2009; 361:569-579.

8. Buchbinder R, Osborne RH, Ebeling PR, et al. A randomized trial of vertebroplasty for painful osteoporotic vertebral fractures. N Engl J Med 2009; 361:557-568. 